\title{
Characteristics of patients initiated on edoxaban in Europe: baseline data from edoxaban treatment in routine clinical practice for patients with atrial fibrillation (AF) in Europe (ETNA-AF-Europe)
}

\author{
Raffaele De Caterina ${ }^{1}$, Peter Kelly ${ }^{2}$, Pedro Monteiro ${ }^{3}$, Jean Claude Deharo ${ }^{4}$, Carlo de Asmundis ${ }^{5}$,
} Esteban López-de-Sá ${ }^{6}$, Thomas W. Weiss ${ }^{7}$, Johannes Waltenberger ${ }^{8}$, Jan Steffel ${ }^{9}$, Joris R. de Groot ${ }^{10}$, Pierre Levy ${ }^{11}$, Ameet Bakhai ${ }^{12}$, Wolfgang Zierhut $^{13}$, Petra Laeis ${ }^{13}$, Michael Kerschnitzki ${ }^{13}$, Paul-Egbert Reimitz ${ }^{13}$, Paulus Kirchhof ${ }^{14,15^{*}}$ (1) and on behalf of the ETNA-AF-Europe investigators

\begin{abstract}
Background: Non-vitamin K antagonist (VKA) oral anticoagulants (NOACs) have substantially improved anticoagulation therapy for prevention of stroke and systemic embolism in patients with atrial fibrillation (AF). The available routine care data have demonstrated the safety of different NOACs; however, such data for edoxaban are scarce. Here, we report baseline characteristics of 13,638 edoxaban-treated patients with AF enrolled between November 2016 and February 2018.
\end{abstract}

Methods: ETNA-AF-Europe is a multinational, multi-centre, post-authorisation, observational study conducted in 825 sites in 10 European countries. Patients will be followed up for four years.

Results: Overall, 13,980 patients were enrolled of which 342 patients were excluded from the analysis. Mean patient age was 73.6 years with an average creatinine clearance of $69.4 \mathrm{~mL} / \mathrm{min}$. $56.6 \%$ were male. The calculated $\mathrm{CHA}_{2} \mathrm{DS}_{2}$-VASC and HAS-BLED mean scores were 3.1 and 2.6, respectively. Overall, 3.3, 14.6 and $82.0 \%$ of patients had low $\left(\mathrm{CHA}_{2} \mathrm{DS}_{2}-\mathrm{VASC}=0\right)$, intermediate $\left(\mathrm{CHA}_{2} \mathrm{DS}_{2}-\mathrm{VASC}=1\right)$ and high $\left(\mathrm{CHA}_{2} \mathrm{DS}_{2}-\mathrm{VASc} \geq 2\right)$ risks of stroke, respectively. High-risk patients (those with prior stroke, prior major bleeding, prior intracranial bleed or $\mathrm{CHA}_{2} \mathrm{DS}_{2}-\mathrm{VASC} \geq 4$ ) comprised $38.4 \%$ of the overall population. For $75.1 \%$ of patients edoxaban was their first anticoagulant prescription, whilst 16.9\% switched from a VKA and 8.0\% from another NOAC. A total of $23.4 \%$ of patients in ETNA-AF-Europe received the reduced dose of edoxaban $30 \mathrm{mg}$. Overall, $83.8 \%$ of patients received an edoxaban dose in line with the criteria outlined in the label.

Conclusion: Edoxaban was predominantly initiated in older, often anticoagulation-naive, unselected European patients with AF, with a good overall adherence to the approved label.

Trial registration: NCT02944019; Date of registration: October 24, 2016.

Keywords: Non-vitamin K antagonist oral anticoagulants, Real-world, Registry, Stroke prevention, Major bleeding, Safety outcomes

\footnotetext{
* Correspondence: p.kirchhof@bham.ac.uk

${ }^{14}$ Institute of Cardiovascular Sciences, University of Birmingham, SWBH and

UHB NHS Trusts, IBR 136, Wolfson Drive, Birmingham B15 2TT, UK

${ }^{15}$ The Atrial Fibrillation NETwork (AFNET), Münster, Germany

Full list of author information is available at the end of the article
}

(c) The Author(s). 2019 Open Access This article is distributed under the terms of the Creative Commons Attribution 4.0 International License (http://creativecommons.org/licenses/by/4.0/), which permits unrestricted use, distribution, and reproduction in any medium, provided you give appropriate credit to the original author(s) and the source, provide a link to the Creative Commons license, and indicate if changes were made. The Creative Commons Public Domain Dedication waiver (http://creativecommons.org/publicdomain/zero/1.0/) applies to the data made available in this article, unless otherwise stated. 


\section{Background}

Atrial fibrillation (AF) is the most prevalent sustained cardiac arrhythmia, and a major cause of ischaemic stroke and disabilities. AF is associated with increased mortality and poses a high burden upon healthcare resources [1]. The risk of strokes related to AF can be substantially reduced through effective anticoagulation. In recent years, non-vitamin $\mathrm{K}$ antagonist (VKA) oral anticoagulants (NOACs) including the direct thrombin inhibitor dabigatran and the direct factor Xa inhibitors rivaroxaban, apixaban, and edoxaban, have greatly improved anticoagulation therapy for the prevention of stroke and systemic embolism in patients with AF. Randomised controlled trials (RCTs) have shown that these agents have at least similar efficacy compared to VKAs, with improved safety, specifically with regards to intracranial haemorrhage [2-6]. In the light of these findings, the European Society of Cardiology 2016 guidelines recommend using NOACs in preference to VKAs when oral anticoagulation is initiated in a patient eligible for a NOAC [7].

Edoxaban, a highly selective, once-daily, direct, reversible inhibitor of Factor Xa was approved for stroke prevention in patients with AF in Europe in 2015, as well as for the treatment and secondary prevention of venous thromboembolism (VTE) in adults. The recommended edoxaban dose is $60 \mathrm{mg}$ once daily with a reduced dose of $30 \mathrm{mg}$ once daily for patients with moderate or severe renal impairment (creatinine clearance $15-50 \mathrm{~mL} / \mathrm{min}$ ), low body weight $(\leq 60 \mathrm{~kg})$, or concomitant use of strong p-glycoprotein inhibitors, including cyclosporine, dronedarone, erythromycin, or ketoconazole [8].

The prescribing of NOACs has increased substantially over the last few years. Recent, real world evidence (RWE) studies have been enrolling patients with AF into various registries such as GLORIA-AF [9], ORBIT AF-II [10], XANTUS [11], GARFIELD-AF [12], DRESDEN NOAC Registry [13], PREFER in AF [14], EORP-AF Registry [15], Danish Registry [16] and retrospective claims analyses [17-20]. These have demonstrated the safety of different NOACs in routine clinical use. Since edoxaban was the last of the four NOACs to enter the market, published data on the use of edoxaban in routine clinical practice are still limited compared with other NOACs [16]. The objective of this analysis was to describe the characteristics of unselected European patients with AF initiated on edoxaban, to compare these characteristics with the European patients enrolled into ENGAGE AF-TIMI 48, and to describe adherence to the dosing recommendations for edoxaban.

\section{Methods}

The Edoxaban Treatment in Routine Clinical Practice for Patients With Non Valvular Atrial Fibrillation (ETNA-AF-
Europe) was designed as part of the risk management plan of edoxaban in order to assess the risks and benefits of the drug in routine care in unselected European patients with AF. ETNA-AF-Europe is part of the global ETNA initiative, which is composed of separate, non-interventional prospective ETNA-AF registries in Europe, East Asia, Brazil and Japan. The final ETNA-AF-Europe protocol was developed based on discussions with, and finally approved by the Pharmacovigilance Risk Assessment Committee (PRAC) of the European Medicines Agency. The primary objective of ETNA-AF Europe is to assess the safety of edoxaban by evaluating bleeding events, including intracranial haemorrhage; drug related adverse events, such as liver adverse events; and cardiovascular $(\mathrm{CV})$ as well as all-cause mortality in routine care patients with AF treated with edoxaban up to 4 years, with regard to onset (relative to treatment with edoxaban) of the event, duration, severity and outcomes.

Details of the design of ETNA-AF-Europe including the statistical rationale have been published [21]. In short, ETNA-AF-Europe is a multinational, multi-centre, post-authorisation, observational study (Clinicaltrials.gov: NCT02944019) conducted in 825 sites (with at least one patient enrolled) in 10 European countries. All patients with non-valvular AF treated with edoxaban according to the summary of product characteristics (SmPC), could participate in the study with prior provision of written informed consent and no simultaneous participation in an interventional trial. No explicit exclusion criteria were defined. Over a period of 3 years, ETNA-AF-Europe enrolled 13,980 patients with AF confirmed within the last 12 months before enrolment. AF had to be confirmed by the investigators by electrical tracing (e.g., ECG, Holter monitoring, pacemaker or other implantable device). Detailed information on AF history and diagnosis, and on previous AF-related therapies was collected, including former anticoagulant treatment with VKAs, NOACs or heparins; previous or current antiplatelet drugs, antiarrhythmic and rate-control drugs and other therapies. The $\mathrm{CHA}_{2} \mathrm{DS}_{2}$-VASc and HAS-BLED scores were both reported by the investigators as well as calculated based on the baseline clinical characteristics of the patients. For the analysis here reported, calculated scores are used. Specific subgroup analyses are planned by edoxaban dose, patient age and country. Figure 1 provides an overview of the patient disposition in ETNA-AF-Europe. Of 13,980 enrolled patients, 13,638 were included in the baseline analysis set. Patients are to be followed up once a year for a total of 4 years.

The patient baseline characteristics from ENGAGE AF-TIMI 48 are used as an external comparator to the baseline data collected in ETNA-AF-Europe to better understand how the usage of edoxaban in routine clinical practice reflects on the trial setting in which 


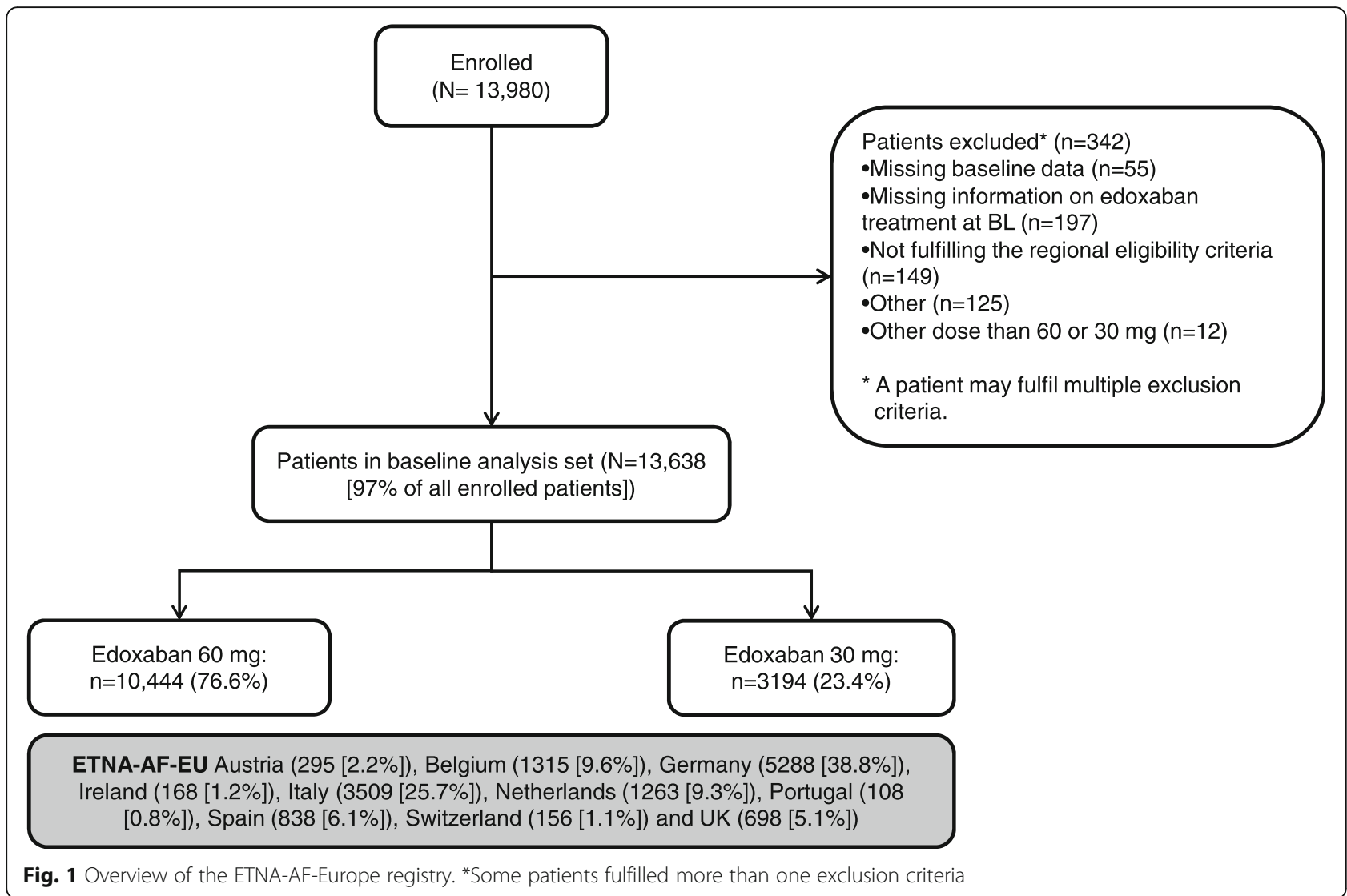

edoxaban was tested. The ENGAGE AF-TIMI 48 cohort used for this purpose includes patients from only those European countries that are also participating in the ETNA-AF-Europe registry.

\section{Results}

\section{Baseline characteristics}

A total of 13,980 patients were enrolled between November 2016 and February 2018 of which 342 patients were excluded from the analysis because they were missing baseline data, missing information on edoxaban treatment at baseline, not fulfilling the regional eligibility criteria, receiving doses other than 60 or $30 \mathrm{mg}$ and other reasons (Fig. 1). Of those, 13,638 patients were evaluated in the analysis of demographics and other baseline characteristics (Fig. 1). The baseline demographics and clinical characteristics of the entire analysis set as well as for the edoxaban $60 \mathrm{mg}$ and $30 \mathrm{mg}$ dose groups separately, are summarised in Table 1. Percountry split of the number of patients was as follows: Austria $(n=295[2.2 \%])$, Belgium $(n=1315$ [9.6\%]), Germany $(n=5288[38.8 \%])$, Ireland $(n=168[1.2 \%])$, Italy $(n=3509 \quad[25.7 \%])$, The Netherlands $(n=1263$ [9.3\%]), Portugal $(n=108[0.8 \%])$, Spain $(n=838[6.1 \%])$, Switzerland $(n=156$ [1.1\%]) and United Kingdom $(n=698$ [5.1\%]) (Fig. 2).
The mean (SD) patient age was $73.6 \pm 9.52$ years (interquartile range Q1-Q3: 68.0-80.0 years) with an average creatinine clearance $(\mathrm{CrCl})$ of $69.4 \mathrm{~mL} / \mathrm{min}$ as calculated according to the Cockroft-Gault equation, and 7718 (56.6\%) of the patients were male. The mean (SD) body weight was $81.0 \pm 17.34 \mathrm{~kg}$ and mean (SD) body mass index was $28.1 \pm 5.14 \mathrm{~kg} / \mathrm{m}^{2}$. Mean $\mathrm{CHA}_{2} \mathrm{DS}_{2}$-VASc and HAS-BLED scores were $3.3 \pm 1.45$ and $1.9 \pm 1.02$ as reported by the investigators, respectively. In contrast, the calculated $\mathrm{CHA}_{2} \mathrm{DS}_{2}$-VASc and HAS-BLED mean scores were $3.1 \pm 1.40$ and $2.6 \pm 1.13$, respectively. Overall, 452 (3.3\%) of patients had a $\mathrm{CHA}_{2} \mathrm{DS}_{2}$-VASc score of 0 ; $1997(14.6 \%)$ of patients had a $\mathrm{CHA}_{2} \mathrm{DS}_{2}$-VASc of 1 and $11,186(82.0 \%)$ of patients had a $\mathrm{CHA}_{2} \mathrm{DS}_{2}$-VASc score of $\geq 2$ (defined according to ESC guidelines [7] (Fig. 3). The first diagnosis of AF had been made over two years before enrolment (mean [Q1-Q3]: 25.7 [29.3-0.4] months) (Table 1). Just over half of the patient population presented with paroxysmal AF, and $19.6 \%$ of the patients presented with permanent AF. Hypertension was the most common cardiovascular comorbidity (76.9\%), followed by valvular heart disease (17.7\%) and heart failure $(5.8 \%)$ (Table 1). Patients with a previous ischaemic stroke accounted for $5.9 \%$, transient ischaemic attack 3.3 , and $4.3 \%$ had a prior myocardial infarction. A prior bleeding event was found in $3.1 \%$ of patients (Table 1). 
Table 1 Baseline demographics and clinical characteristics of patients included in ETNA-AF-Europe

\begin{tabular}{|c|c|c|c|}
\hline Characteristic & Total & $\begin{array}{l}\text { Edoxaban } \\
60 \text { mg OD } \\
\end{array}$ & $\begin{array}{l}\text { Edoxaban } \\
30 \mathrm{mg} \text { OD }\end{array}$ \\
\hline Patients, N (\%) & $13,638(100)$ & $10,444(76.6)$ & 3194 (23.4) \\
\hline Male, \% & 56.6 & 60.6 & 43.5 \\
\hline Age, years, mean (SD) & $73.6(9.52)$ & $71.8(9.23)$ & $79.6(7.87)$ \\
\hline \multicolumn{4}{|l|}{ By age sub-groups, $\%$} \\
\hline$<65$ years & 15.4 & 18.8 & 4.1 \\
\hline $65-74$ years & 33.7 & 38.5 & 18.0 \\
\hline $75-84$ years & 40.3 & 37.3 & 50.4 \\
\hline$\geq 85$ years & 10.6 & 5.4 & 27.5 \\
\hline Body weight, kg, mean (SD) & $81.0(17.34)$ & $83.5(16.77)$ & $72.8(16.63)$ \\
\hline BMl, kg/m², mean (SD) & $28.1(5.14)$ & $28.6(5.06)$ & $26.5(5.07)$ \\
\hline SBP, mmHg, mean (SD) & $133.4(18.04)$ & $133.7(17.90)$ & $132.6(18.46)$ \\
\hline DBP, mmHg, mean (SD) & $78.3(10.90)$ & $79.0(10.91)$ & $76.2(10.60)$ \\
\hline Current smoking, \% & 6.3 & 6.9 & 4.4 \\
\hline \multicolumn{4}{|l|}{ Alcohol, \% } \\
\hline No & 44.8 & 42.0 & 54.0 \\
\hline $\begin{array}{l}\mathrm{CrCl} \text { (reported), mL/min, } \\
\text { mean (SD) }\end{array}$ & $69.4(24.23)$ & $75.5(22.65)$ & $50.8(18.90)$ \\
\hline
\end{tabular}

By $\mathrm{CrCl}$ subgroups, \%

$\begin{array}{llll}<15 & 0.6 & 0.7 & 0.2 \\ (15,30) & 1.9 & 0.3 & 6.8 \\ (30,50) & 18.0 & 6.7 & 52.9 \\ (50,80) & 48.2 & 53.6 & 31.6 \\ \geq 80 & 31.3 & 38.7 & 8.5\end{array}$

Patients with dose reduction criteria, \%

\begin{tabular}{|c|c|c|c|}
\hline Body weight $\leq 60 \mathrm{~kg}, \%$ & 10.4 & 5.0 & 27.6 \\
\hline $\mathrm{CrCl} 15-50 \mathrm{~mL} / \mathrm{min}, \%$ & 19.9 & 7.0 & 59.7 \\
\hline $\begin{array}{l}\text { Concomitant use of P-gp } \\
\text { inhibitors }{ }^{\mathrm{a}} \%\end{array}$ & 1.0 & 0.9 & 1.5 \\
\hline (calc.) $\mathrm{CHADS}_{2}$, mean (SD) & $1.7(1.07)$ & $1.6(1.05)$ & $2.1(1.03)$ \\
\hline $\begin{array}{l}\text { (calc.) } \mathrm{CHA}_{2} \mathrm{DS}_{2}-\mathrm{VASC} \text {, mean } \\
\text { (SD) }\end{array}$ & $3.1(1.40)$ & $2.9(1.37)$ & $3.8(1.26)$ \\
\hline $\mathrm{CHA}_{S} \mathrm{DS}_{2}$-VASc score $=0, \%$ & 2.3 & 2.8 & 0.3 \\
\hline $\mathrm{CHA}_{5} \mathrm{DS}_{2}$-VASc score $=1, \%$ & 10.3 & 12.6 & 2.5 \\
\hline (calc.) HAS-BLED, mean & $2.6(1.13)$ & $2.4(1.11)$ & $3.0(1.10)$ \\
\hline \multicolumn{4}{|l|}{ Frailty $^{\mathrm{b}}, \%$} \\
\hline Yes & 10.6 & 6.1 & 25.3 \\
\hline No & 82.7 & 87.3 & 67.4 \\
\hline Not known & 6.7 & 6.6 & 7.3 \\
\hline \multicolumn{4}{|l|}{ Previous history of CV disease, \% } \\
\hline Hypertension & 76.9 & 75.9 & 80.0 \\
\hline Congestive heart failure & 5.8 & 4.7 & 9.5 \\
\hline Myocardial infarction & 4.3 & 3.7 & 6.2 \\
\hline Angina pectoris & 1.5 & 1.3 & 2.1 \\
\hline Valvular disease & 17.7 & 16.2 & 22.9 \\
\hline
\end{tabular}

Table 1 Baseline demographics and clinical characteristics of patients included in ETNA-AF-Europe (Continued)

\begin{tabular}{clll}
\hline Characteristic & Total & $\begin{array}{l}\text { Edoxaban } \\
60 \mathrm{mg} \mathrm{OD}\end{array}$ & $\begin{array}{l}\text { Edoxaban } \\
30 \mathrm{mg} \mathrm{OD}\end{array}$ \\
\hline Peripheral artery disease & 3.3 & 2.8 & 5.2 \\
$\begin{array}{l}\text { Previous history of diabetes } \\
\text { mellitus, \% }\end{array}$ & 21.9 & 20.5 & 26.7
\end{tabular}

Previous history of stroke and $\mathrm{ICH}, \%$

$\begin{array}{llll}\text { Ischaemic stroke } & 5.9 & 5.6 & 6.9 \\ \text { Stroke, unknown } & 0.6 & 0.5 & 0.8 \\ \text { Transient ischaemic attack } & 3.3 & 3.2 & 3.7 \\ \text { Intracranial haemorrhage } & 0.5 & 0.4 & 0.6\end{array}$

Previous history of bleeding, \%

$\begin{array}{llll}\text { Any bleeding } & 3.1 & 2.5 & 5.2 \\ \begin{array}{l}\text { Gl bleeding (Major or } \\ \text { CRNM) }\end{array} & 0.8 & 0.5 & 1.7 \\ \quad \text { Major } & 1.0 & 0.8 & 1.6 \\ \text { CRNM } & 1.0 & 0.8 & 1.8 \\ \quad \text { Minor } & 1.1 & 0.9 & 1.8 \\ \text { Renal disease (including } & 27.0 & 19.5 & 51.6\end{array}$

dialysis), \%

Current AF type, \%

$\begin{array}{llll}\text { Paroxysmal } & 53.6 & 54.5 & 50.4 \\ \text { Persistent } & 24.4 & 25.3 & 21.2 \\ \text { Long-standing persistent } & 2.4 & 2.3 & 2.9 \\ \text { Permanent } & 19.6 & 17.8 & 25.5\end{array}$

Time since first AF diagnosis, months

$\begin{array}{llll}\text { Mean (SD) } & 25.7(46.88) & 24.9(47.01) & 28.4(46.37) \\ \text { IQ, Q1-Q3 } & 29.3-0.4 & 26.5-0.4 & 37.5-0.6\end{array}$

Previous use of AF relevant medication, \%

$\begin{array}{llll}\text { VKA } & 16.9 & 16.3 & 18.9 \\ \text { NOAC (other) } & 8.0 & 6.9 & 11.6 \\ \text { Antiarrrhythmics } & 5.0 & 5.0 & 4.8 \\ \text { Antiplatelet } & 15.1 & 14.8 & 16.2\end{array}$

${ }^{a}$ P-gp inhibitors requiring edoxaban dose reduction: cyclosporine, dronedarone, erythromycin, ketoconazole

${ }^{\mathrm{b}}$ There was no specific definition for frailty; it was left to the discretion of the physician to categorise a patient as frail

$A F$ atrial fibrillation, $B M I$ body mass index, $C K D$ chronic kidney disease, $\mathrm{CrCl}$ creatinine clearance, CRNM clinically relevant non-major, $C V$ cardiovascular, $D B P$ diastolic blood pressure, G/ gastrointestinal, ICH intracranial haemorrhage, IQ interquartile range, NOAC non-vitamin $\mathrm{K}$ antagonist oral anticoagulant, NSAIDs non-steroidal anti-inflammatory drugs, $O D$ once daily, P-gp P-glycoprotein, SBP systolic blood pressure, $S D$ standard deviation, VKA vitamin $\mathrm{K}$ antagonist

Overall, 10,242 (75.1\%) patients were not on anticoagulation prior to initiating edoxaban, whilst 2305 (16.9\%) switched from a VKA (Fig. 4): 904 (39.2\%) from warfarin, $732(31.8 \%)$ from acenocumarol and 658 (28.5\%) from phenprocoumon. Furthermore, 1091 (8.0\%) switched from another NOAC: 341 (31.3\%) from apixaban, 283 (25.9\%) from dabigatran and 453 (41.5\%) from rivaroxaban and 14 (1.3\%) from others (not specified). 


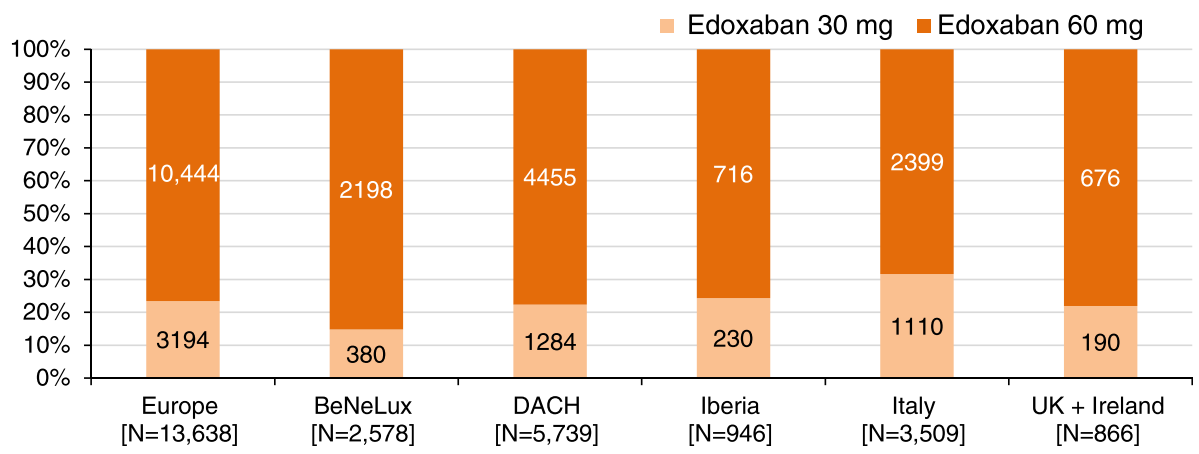

Fig. 2 Number of patients per region (by dose) in the European ETNA-AF registry. BeNeLux, Belgium, the Netherlands, and Luxembourg; DACH, Germany, Austria, Switzerland

Of the 13,638 patients, 10,444 (76.6\%) received edoxaban $60 \mathrm{mg}$ and $3194(23.4 \%)$ received $30 \mathrm{mg}$ once daily. Adherence to the edoxaban SmPC was $83.8 \%$, with 11 , $432 / 13,638$ patients being dosed in line with the edoxaban label. Of the 2206 patients (16.2\%) not dosed following the label, 1031 patients (7.5\%) received 30 mg edoxaban without the criteria for dose reduction, whereas 1175 patients (8.6\%) received edoxaban 60 $\mathrm{mg}$ even though at least one of the dose reduction criteria was present.

a

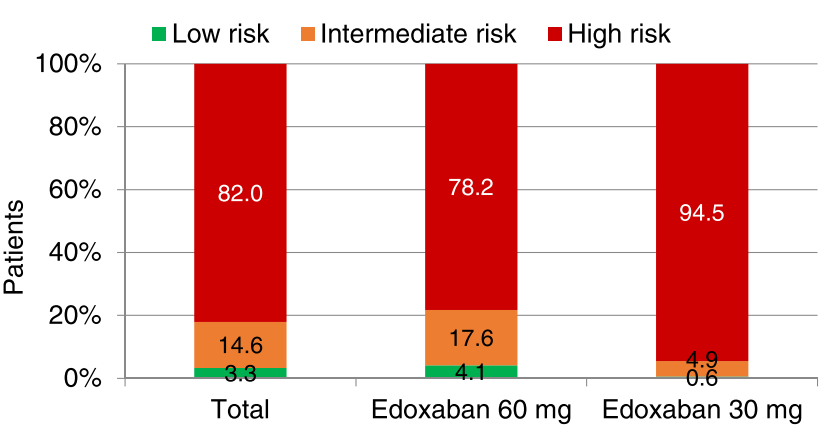

$\mathrm{CHA}_{2} \mathrm{DS}_{2}-\mathrm{VASc}^{*}$

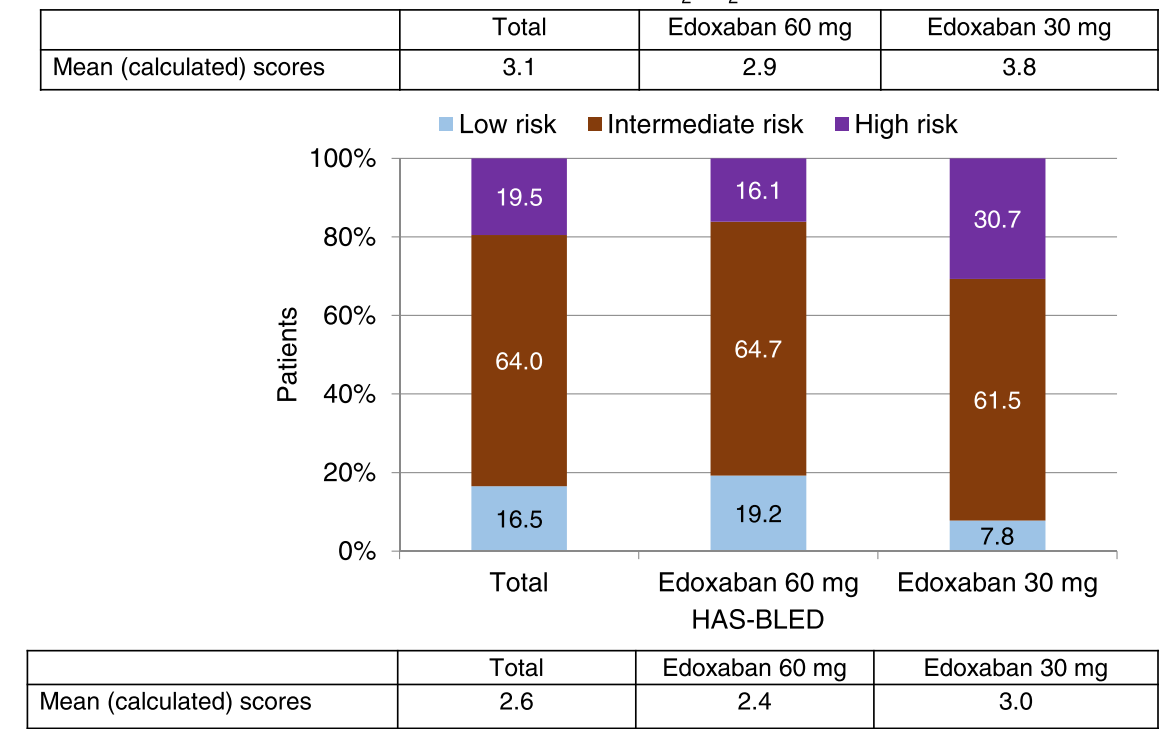

Fig. 3 Mean $\mathrm{CHA}_{2} \mathrm{DS}_{2}-\mathrm{VASC}$ and HAS-BLED [calculated] score distribution by dose groups. $\mathbf{a} \mathrm{CHA}_{2} \mathrm{DS}_{2}-\mathrm{VASC}$ score distribution ${ }^{(7)}$ : Low risk: Score $=0$ for men, 1 for women. Intermediate risk: Score = 1 for men, 2 for women. High risk: Score $\geq 2$ for men, $>2$ for women. $\mathbf{b}$ HAS-BLED score distribution: Low risk: Score $<2$. Intermediate risk: Score 2-3. High risk: Score $\geq 4$ 


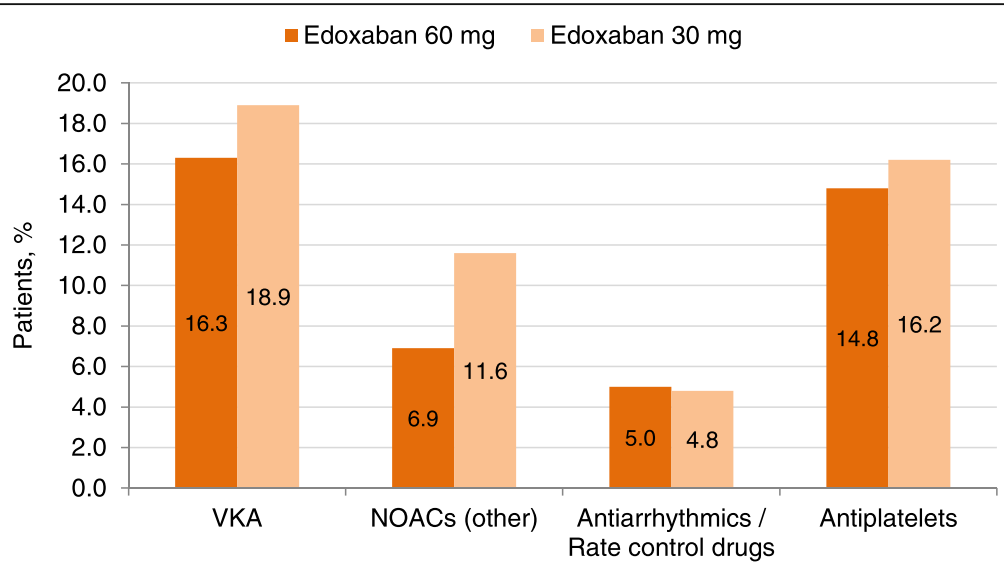

Fig. 4 Percentage of patients who received antithrombotic or antiarrhythmic treatment prior to enrolment. AF, atrial fibrillation; BL, baseline; NOAC, non-vitamin $\mathrm{K}$ antagonist oral anticoagulant; VKA, vitamin $\mathrm{K}$ antagonist

There were considerable differences in the characteristics of patients receiving the $60 \mathrm{mg}$ vs the $30 \mathrm{mg}$ dose. The mean baseline $\mathrm{CrCl}$ was $75.5 \mathrm{~mL} / \mathrm{min}$ and $50.8 \mathrm{~mL} /$ min for the edoxaban $60 \mathrm{mg}$ and $30 \mathrm{mg}$ dose groups, respectively. $60.2 \%$ of patients in the edoxaban $30 \mathrm{mg}$ dose group, compared to only $8.3 \%$ in the edoxaban 60 $\mathrm{mg}$ group, had a baseline $\mathrm{CrCl}$ of $\leq 50 \mathrm{ml} / \mathrm{min}$ (Fig. 5). A history of chronic kidney disease was reported in 19.5 and $51.6 \%$ of patients receiving edoxaban $60 \mathrm{mg}$ and 30 mg doses, respectively.

High-risk patients, defined in the ETNA-AF-Europe registry as patients with a high risk for either stroke or bleeding based on presence of either a prior stroke, prior major bleeding or prior $\mathrm{ICH}$, or a $\mathrm{CHA}_{2} \mathrm{DS}_{2}$-VASc score $\geq 4$, comprised $38.4 \%$ of the overall population; with 32.1 and $58.9 \%$ of those receiving edoxaban $60 \mathrm{mg}$ and $30 \mathrm{mg}$ doses, respectively categorised as high-risk patients (Fig. 6). Overall, $1442(10.6 \%)$ of patients were considered frail, more than half of those were receiving edoxaban $30 \mathrm{mg}$ once daily. There was no specific definition for frailty; it was left to the discretion of the physician to categorise a patient as frail.

A large majority of patients $(77.8 \%)$ receiving edoxaban $30 \mathrm{mg}$ versus $42.7 \%$ of patients on edoxaban $60 \mathrm{mg}$ were aged $\geq 75$ years. $\mathrm{CHA}_{2} \mathrm{DS}_{2}$-VASc scores $\geq 4$ were more frequent in patients receiving edoxaban $30 \mathrm{mg}$ (58.2\%) versus edoxaban $60 \mathrm{mg}$ dose (31\%) (Fig. 3).

A greater proportion of patients with a previous history of CV disease received edoxaban $30 \mathrm{mg}$ as compared with edoxaban $60 \mathrm{mg}$ dose. Ischaemic stroke was reported in $6.9 \%$ versus $5.6 \%$ in the edoxaban $30 \mathrm{mg}$ versus $60 \mathrm{mg}$ dose group and myocardial infarction in $6.2 \%$ versus $3.7 \%$, respectively (Table 1 ). Likewise, a history of any bleeding was documented more frequently for the edoxaban $30 \mathrm{mg}$ versus edoxaban $60 \mathrm{mg}$ dose ( $5.2 \%$ versus $2.5 \%$, respectively).

\section{Discussion}

The baseline characteristics of the ETNA-AF-Europe registry here reported indicate that among the 13,980 patients enrolled, there is a consistent percentage of

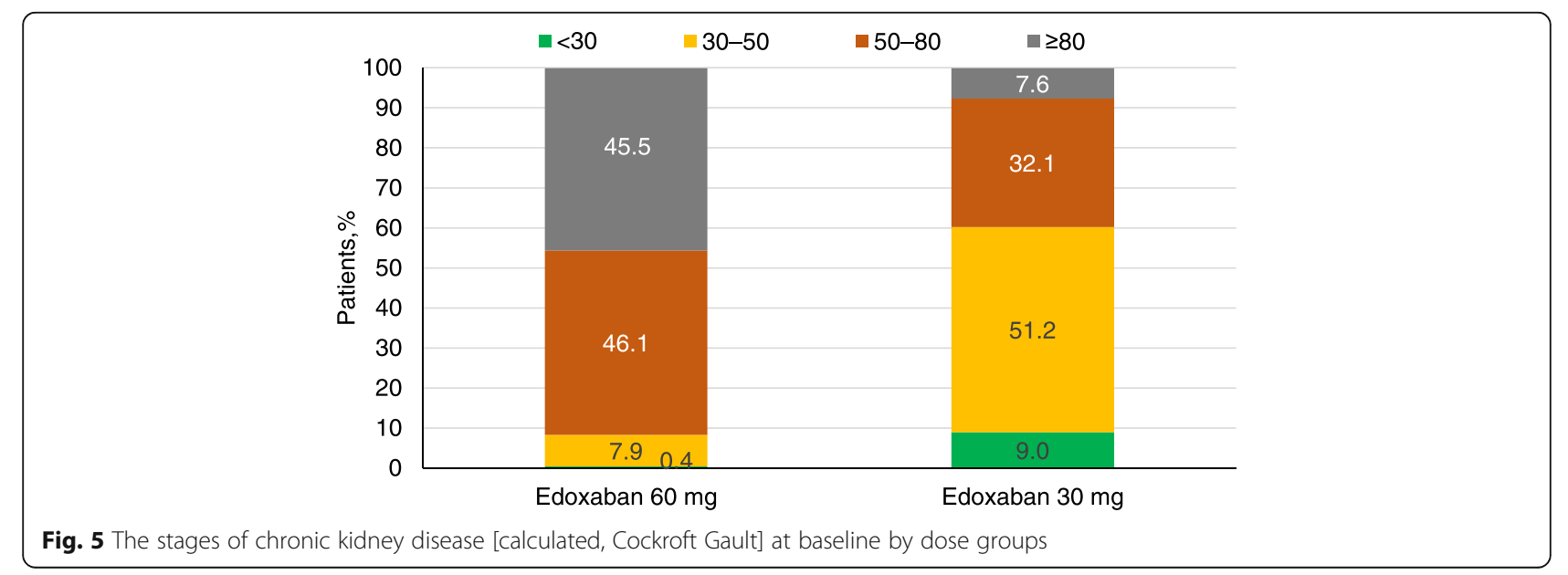




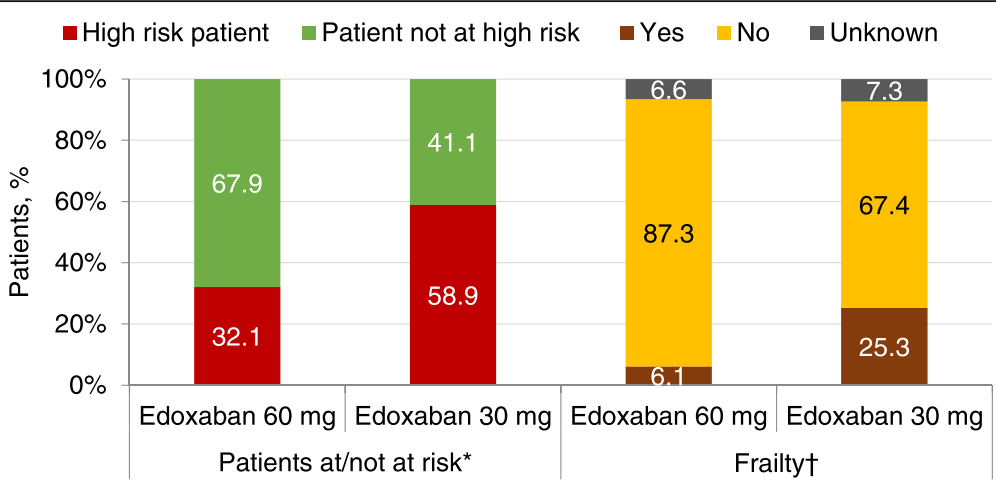

Fig. 6 Difficult-to-treat patients at baseline categorised by dose groups. *A patient is considered as a high risk patient if he/she has at least one of the following: prior stroke, prior major bleeding, prior $\mathrm{ICH}$ or (calculated) $\mathrm{CHA}_{2} \mathrm{DS}_{2}-\mathrm{VASC} \geq 4{ }^{\dagger}{ }^{\dagger}$ There was no specific definition for frailty; it was left to the discretion of the physician to categorise a patient as frail

elderly patients, with $50.9 \%$ of them $\geq 75$ years of age. Most enrolled patients are naïve to prior anticoagulation (75.1\%) and more than half have paroxysmal AF (53.6\%). The use of the $60 \mathrm{mg}$ full dose is overall predominant (76.6\%), but among the high risk and frail patients, the use of $30 \mathrm{mg}$ is higher (58.9 and 56\%, respectively). For randomisation in ENGAGE AF-TIMI 48, a $\mathrm{CHADS}_{2}$ score of 2 or more was required, whereas the approved European Medicines Agency label requires only a $\mathrm{CHADS}_{2}$ score of 1 to be eligible for treatment with edoxaban. Daiichi Sankyo, the ETNA-AF steering committee and the European Medicines Agency have therefore jointly designed the ETNA-AF-Europe study to provide important additional safety information on the use of edoxaban in routine care.

The baseline demographics and clinical characteristics of patients receiving edoxaban in ETNA-AF-Europe were broadly similar to those enrolled in the European cohort of the ENGAGE AF-TIMI 48 trial, yet there were some notable differences (Table 2). The mean $\mathrm{CHADS}_{2}$ and $\mathrm{CHA}_{2} \mathrm{DS}_{2}$-VASc scores were considerably lower in the ETNA-AF-Europe registry compared with the ENGAGE AF-TIMI trial $\left(\mathrm{CHADS}_{2}: 1.7\right.$ versus 2.8 and $\mathrm{CHA}_{2} \mathrm{DS}_{2}$-VASc: 3.1 versus 4.2 , respectively) and patients more frequently presented with paroxysmal AF (53.6\% versus $26.6 \%$, respectively) (Table 2). The lower mean $\mathrm{CHADS}_{2}$ score in ETNA-AF-Europe likely reflected the difference between the European label of edoxaban $\left(\mathrm{CHADS}_{2} \geq 1\right)$ and the inclusion criteria of ENGAGE AFTIMI 48 (a score of 2 or higher on the $\mathrm{CHADS}_{2}$ risk assessment), and may also hint to a cautious approach of prescribing physicians to newly marketed medicines.

In keeping with the different inclusion criteria, cardiovascular comorbidities such as hypertension, congestive heart failure and history of ischaemic stroke were more common in patients in the European ENGAGE AFTIMI 48 trial versus those included in ETNA-AF-
Europe. Also, prior CV events such as ischaemic stroke and transient ischaemic attack were fewer in ETNA-AFEurope versus the ENGAGE AF-TIMI 48 trial.

There are important markers of high risk of complications in the ETNA-AF-Europe population. Patients receiving edoxaban in routine care are slightly older than those enrolled in the ENGAGE AF-TIMI 48 trial. The population in the ETNA-AF-Europe analysis had a higher bleeding risk than those recorded in the corresponding countries in ENGAGE AF-TIMI 48, with mean HAS-BLED scores of 2.5 and 1.6 in ETNA-AF-Europe and ENGAGE AF-TIMI 48, respectively (Table 2). The ETNA-AF-Europe population shows a slightly lower creatinine clearance and a higher proportion of patients with chronic kidney disease (Table 2). These findings underpin the general assumption that patients at a higher risk are under-represented in phase III trials, including those of anticoagulants for stroke prevention in AF.

In ETNA-AF-Europe, the mean investigator-reported $\mathrm{CHA}_{2} \mathrm{DS}_{2}$-VASc score was higher than the formally calculated score whereas the mean investigator reported HAS-BLED score was lower than the formally calculated score. These findings suggest that physicians may have overestimated the risk of stroke and underestimated the risk of bleeding in the ETNA-AF-Europe population. Specifically, the HAS-BLED score may potentially not be widely used in daily clinical practice so the physicians' lack of familiarity with this score could have played a role in the underestimation of bleeding risk. Further investigations in the ETNA-AF-Europe database for the potential reasons related to a wrong perception of risks such as consideration of specific comorbidities or patient history may bring more clarity to this finding. For now, this finding highlights the continued need for educating health care professionals and patients in Europe concerning anticoagulation [22]. 
Table 2 Comparison of baseline characteristics of patients in the ETNA-AF-Europe registry and ENGAGE AF-TIMI 48 trial

\begin{tabular}{|c|c|c|}
\hline & $\begin{array}{l}\text { ETNA-AF-Europe } \\
\qquad N=13,638\end{array}$ & $\begin{array}{c}\text { ENGAGE AF-TIMI } \\
48^{\mathrm{a}} \text { Corresponding } \\
\text { ETNA-AF countries }^{\mathrm{b}} \\
\quad N=2123\end{array}$ \\
\hline Age $(y)$, mean (SD) & $73.6(9.52)$ & $72.7(8.09)$ \\
\hline \multicolumn{3}{|l|}{ By age sub-groups, n (\%) } \\
\hline$<65$ years & 2096 (15.4) & $344(16.2)$ \\
\hline $65-75$ years & $4598(33.7)$ & $764(36.0)$ \\
\hline$\geq 75$ years & $6939(50.9)$ & $1015(47.8)$ \\
\hline Male, \% & 56.6 & 62.4 \\
\hline BMI $\left(\mathrm{kg} / \mathrm{m}^{2}\right)$, mean $(\mathrm{SD})$ & $28.1(5.14)$ & $29.8(5.39)$ \\
\hline Weight (kg), mean (SD) & $81.0(17.34)$ & $85.4(17.47)$ \\
\hline eCrCl (mL/min), mean (SD) & $69.4(24.23)$ & $75.5(28.96)$ \\
\hline $\mathrm{CHADS}_{2}$, mean (SD) & $1.7(1.07)$ & $2.8(0.93)$ \\
\hline $\begin{array}{l}\mathrm{CHA}_{2} \mathrm{DS}_{2} \text {-VASc, calculated, } \\
\text { mean (SD) }\end{array}$ & $3.1(1.40)$ & $4.2(1.31)$ \\
\hline HAS-BLED, mean (SD) & $2.6(1.13)$ & $1.6(0.92)$ \\
\hline Hypertension, \% & 76.9 & 92.4 \\
\hline Diabetes, \% & 21.9 & 39.1 \\
\hline Myocardial infarction, \% & 4.3 & 2.9 \\
\hline Ischaemic stroke, \% & 5.9 & 15.5 \\
\hline Transient ischaemic attack, \% & 3.3 & 11.9 \\
\hline Congestive heart failure, $\%$ & 5.8 & 48.2 \\
\hline Paroxysmal AF, \% & 53.6 & 26.6 \\
\hline Persistent AF, \% & 24.4 & 24.1 \\
\hline Permanent AF, \% & 19.6 & 49.4 \\
\hline $\begin{array}{l}\text { Renal disease (including } \\
\text { dialysis), \% }\end{array}$ & 27.0 & 11.9 \\
\hline \multicolumn{3}{|c|}{$\begin{array}{l}\text { amITT } \\
\text { bBelgium, Switzerland, Germany, Spain, United Kingdom, Italy, Netherlands, Portugal } \\
\text { \% values are based on non-missing data } \\
A F \text { atrial fibrillation, BMI body mass index, CHADS } 2 \text { Congestive heart failure, } \\
\text { Hypertension, Age } \geq 75 \text { years, Diabetes mellitus, Stroke (double weight), eCrCl } \\
\text { estimated creatinine clearance (Cockcroft-Gault), ENGAGE AF-TIMI } 48 \text { study } \\
\text { Effective aNticoaGulAtion with Factor Xa next GEneration in Atrial Fibrillation- } \\
\text { Thrombolysis In Myocardial Infarction study 48, ETNA-AF Edoxaban Treatment in } \\
\text { routine cliNical prActice, mITT modified intent-to-treat, SD standard deviation }\end{array}$} \\
\hline
\end{tabular}

In routine clinical practice, it is commonly observed that NOACs are frequently prescribed at a lower dose despite not meeting the dose reduction criteria listed in the label $[23,24]$. Therefore, compared with the pivotal clinical trials, the use of reduced NOAC doses in daily clinical practice appears to be more frequent $[25,26]$. A retrospective study reported the use of a reduced dose of NOACs in $56.8 \%$ of patients with no clear indication, and use of non-reduced dose in $43.2 \%$ of patients while indicated [25]. Such findings suggest the need to strengthen dosing education of NOACs in clinical practice. Notably, the distribution of the edoxaban $60 \mathrm{mg}$ and $30 \mathrm{mg}$ dosing in ETNA-AF-Europe was largely in line with the distribution within corresponding countries from ENGAGE AF-TIMI 48; a total of $23.4 \%$ of patients in ETNA-AF-Europe received the reduced dose of edoxaban $30 \mathrm{mg}$ which was similar to the percentage of patients $(21.8 \%)$ eligible for dose reduction in the European cohort of the ENGAGE AF-TIMI 48 trial.

Among the edoxaban dose reduction criteria listed in the $\mathrm{SmPC}$, reduced renal clearance $\leq 50 \mathrm{ml} / \mathrm{min}$ is by far the most frequently applied criterion in a Western population [27], whereas low body weight (below $60 \mathrm{~kg}$ ) or concomitant use of certain P-gp-inhibitors are less often met. The ETNA programme will provide information on patients characteristics in other parts of the world, where weight $<60 \mathrm{~kg}$ may be more common.

Since poor renal function is associated with old age and various comorbidities, the differences in baseline characteristics of patients receiving edoxaban $30 \mathrm{mg}$ and $60 \mathrm{mg}$ groups are broadly in line with expectations. History of congestive heart failure, myocardial infarction, angina pectoris and valvular heart disease was more commonly observed in the $30 \mathrm{mg}$ dose group as compared with the patients receiving the $60 \mathrm{mg}$ dose (Table 1). High risk patients, predefined as those with prior stroke, prior major bleed, prior intracranial haemorrhage, or $\mathrm{CHA}_{2} \mathrm{DS}_{2}$-VASc score $\geq 4$ accounted for $38.4 \%$ of patients in ETNA-AF and a higher proportion of these difficult-to-treat patients received the edoxaban $30 \mathrm{mg}$ dose versus edoxaban $60 \mathrm{mg}$ dose in ETNA-AFEurope. The same was true for patients considered frail by the investigator.

In ETNA-AF-Europe, a high adherence of $83.8 \%$ to the dose selection criteria according to the SmPC was observed. The consistent dosing criteria for edoxaban across all indications may have contributed to this finding. Nevertheless, not all patients were dosed according to the label; approximately $16 \%$ of patients received a dose that was not in line with the SmPC, with 7.5\% ( $n=$ 1031) of patients receiving edoxaban $30 \mathrm{mg}$ instead of the recommended $60 \mathrm{mg}$, and $8.6 \%(n=1175)$ of patients receiving $60 \mathrm{mg}$ instead of the recommended $30 \mathrm{mg}$. The rationale for prescribing the $60 \mathrm{mg}$ dose despite the presence of a dose reduction criterion is currently unclear and needs further analyses. The general overestimation of the $\mathrm{CHA}_{2} \mathrm{DS}_{2}$-VASc score combined with the underestimation of the HAS-BLED score by the ETNAAF-Europe investigators or unavailability of renal function at the time of prescribing, may both have played a role in this context. Future analyses on specific characteristics of these patients such as very high body weight or certain co-morbidities are warranted. Furthermore, patient age, creatinine clearance or body weight close to the indicated dose reduction threshold, or the fear of iatrogenic bleeding in a fragile patient population that already had a frequent history of bleeding may have 
contributed to the choice of the lower edoxaban dose deviating from the label. In support, perceived frailty of patients was more frequently reported in patients receiving the $30 \mathrm{mg}$ dose (Fig. 6), which could have influenced the prescribing pattern independent of the criteria in the label. Publications such as the 2018 European Heart Rhythm Association Practical Guide [28] have certainly helped in raising awareness regarding the need for appropriate dosing of NOACs. The details in the EHRA guide differ somewhat from the criteria outlined in the SmPC. It will be interesting to apply these additional criteria to the ETNA-AF-Europe population and this study provides an opportunity to look into this.

It is widely accepted that randomised trials are the gold standard for ascertaining the efficacy and safety of a given therapy. However, RCTs are not fully representative of an unselected real-world population due to their highly controlled settings. For example, in all phase $3 \mathrm{AF}$ NOAC trials, patients with very high bleeding risk were largely excluded, resulting in paucity of data on these patients. In addition, the patient population specified in the label is usually broader than the key inclusion criteria of the pivotal trials. On the other hand, a prospective registry might also have limitations, due to the lack of randomisation: physicians might tend to prescribe a certain therapy to a specific category of patients, and furthermore patients could opt in for enrolment. These features might cause a selection bias that may hamper the generalizability of the observed results.

In our registry, the majority of $\mathrm{AF}$ patients were anticoagulation-naïve prior to the initiation of edoxaban. Patients were also reported to switch from another NOAC to edoxaban, illustrating a clinical need for more than one NOAC for stroke prevention in AF. The recent registry data have shown that $95 \%$ of edoxaban users enrolled via the Danish National Prescription Registry [16] had previously received some anticoagulant treatment, with $77 \%$ switching directly from another anticoagulant treatment to edoxaban (45\% from VKA and 32\% from other NOACs). In this registry, users of edoxaban were comparable with users of other NOACs, with a median age of 75 versus $72-76$ years and $57 \%$ versus $53-59 \%$ males. These baseline results are the first consistent evidence of real-world use of once daily edoxaban, the most recently approved NOAC, in Europe.

\section{Conclusion}

Edoxaban is predominantly used in routine clinical practice for older AF patients, mostly anticoagulation-naïve with dosing in line with recommendations in the approved European Union label for a high proportion of patients $(84 \%)$. The patient population enrolled in ETNA-AF-Europe is similar to those enrolled in the ENGAGE AF TIMI-48 trial and showed a similar proportional usage of the reduced $30 \mathrm{mg}$ edoxaban dose. Differences between the populations include slightly higher age, more patients with paroxysmal AF, lower $\mathrm{CHA}_{2} \mathrm{DS}_{2}$-VASc score, higher bleeding risk, less cardiovascular comorbidities and more renal impairment in ETNA-AF-Europe.

\section{Abbreviations}

AF: Atrial fibrillation; CrCl: Creatinine clearance; CV: Cardiovascular; ETNA-AFEurope: Edoxaban treatment in routine clinical practice for patients with non valvular atrial fibrillation; NOACs: Non-vitamin K antagonist (VKA) oral anticoagulants; PRAC: Pharmacovigilance risk assessment committee; RCTs: Randomised controlled trials; RWE: Real world evidence; SmPC: Summary of product characteristics; VTE: Venous thromboembolism

\section{Acknowledgements}

Editorial support was provided by Shelley Narula from inScience Communications, Springer Healthcare Ltd., UK, and was funded by Daiichi Sankyo Europe GmbH, Munich, Germany in accordance with Good Publication Practice (GPP3) guidelines (http://www.ismpp.org/gpp3).

\section{Authors' contributions}

RdC, PK, PM, JCD, CdA, ELdS, TW, JW, JS, JdG, PL, AB, PK, PL and WZ contributed to the study design. RdC, PK, PM, JCD, CdA, ELdS, TW, JW, JS, $J d G, P L, A B, P K$ and ETNA-AF investigators contributed to data acquisition. $\mathrm{PER}, \mathrm{WZ}, \mathrm{PL}, \mathrm{MK}, \mathrm{RDC}$ and PK were responsible for statistical analysis. RdC, PK, PM, JCD, CdA, ELdS, TW, JW, JS, JdG, PL, AB, PK, WZ and MK were responsible for data interpretation. All authors drafted the work or substantively revised it, and approved the final manuscript. All authors agreed both to be personally accountable for the author's own contributions and to ensure that questions related to the accuracy or integrity of any part of the work, even ones in which the author was not personally involved, are appropriately investigated, resolved, and the resolution documented in the literature.

\section{Funding}

The design of the study and collection, analysis, and interpretation of data and editorial writing support was funded by Daiichi Sankyo Europe $\mathrm{GmbH}$, Munich, Germany.

\section{Availability of data and materials}

The data that support the findings of this study are available from Daiichi Sankyo but restrictions apply to the availability of these data, which were used under license for the current study, and so are not publicly available. Data are however available from the authors upon reasonable request and with permission of Daiichi Sankyo.

\section{Ethics approval and consent to participate}

The study was approved by the institutional review boards and independent ethics committees for all participating centres. All participants provided written informed consent.

\section{Consent for publication}

Not applicable.

\section{Competing interests}

Raffaele De Caterina co-authored ESC Guidelines on Atrial Fibrillation 20102012; acted as a Steering Committee member and National Coordinator for Italy, and co-authored manuscripts published on APPRAISE-2, ARISTOTLE, AVERROES, ENGAGE-AF and Re-DUAL PCI. RDC has received fees, honoraria and research funding from Sanofi-Aventis, Boehringer Ingelheim, Bayer, Bristol-Myers Squibb/Pfizer, Daiichi-Sankyo, Novartis, Portola, Roche and Merck.

Peter Kelly has received speaker's honoraria for lectures given at meetings sponsored by Daiichi-Sankyo. He is the Lead Investigator of the HRB Stroke Clinical Trials Network Ireland, which has received grant funding from the Irish government, Irish Heart Foundation, Daiichi Sankyo, Bayer, Boehringer Ingelheim, Pfizer, Bristol-Myers Squibb, Amgen and A Menarini.

Pedro Monteiro is an ETNA-AF investigator, and has received lecture and research fees from Daiichi-Sankyo, Bayer, Boehringer Ingelheim and Pfizer/BMS. 
Jean Claude Deharo has received honoraria for lectures from Bayer, Boehringer Ingelheim and Bristol-Myers Squibb. JCD has also received research grants from Boston Scientific, Sorin Group, Biotronik and Abbott. Carlo de Asmundis has received compensation for teaching purposes and proctoring from Medtronic, Abbott, Biotronik, Atricure, Cardiotek, Biosense Webster and research grants on behalf of the centre from Biotronik, Medtronic, St Jude Medical Abbot, Livanova, Boston Scientific Biosense Webster

Esteban López-de-Sá reports grants and non-financial support from ZOLL Medical Corporation, grants from Boehringer Ingelheim, grants, personal fees and non-financial support from Servier, personal fees and non-financial support from Daiichi Sankyo, personal fees and non-financial support from Rovi, personal fees from BARD, during the conduct of the study.

Thomas W. Weiss has received fees, honoraria and research funding from Astra-Zeneca, Boehringer Ingelheim, Bayer, Bristol-Myers Squibb/Pfizer, Daiichi-Sankyo, Medtronic, Menarini Pharma, Novartis and Sanofi-Aventis. Johannes Waltenberger reports personal fees from Bayer Vital, personal fees from Berlin Chemie, personal fees from Boehringer Ingelheim, personal fees from Daiichi Sankyo, personal fees from Sanofi Aventis, personal fees from Vifor Pharma Deutschland, during the conduct of the study. Jan Steffel has received consultant and / or speaker fees from Abbott, Amgen, Astra-Zeneca, Atricure, Bayer, Biosense Webster, Biotronik, Boehringer-Ingelheim, Boston Scientific, Bristol-Myers Squibb, Daiichi Sankyo, Medscape, Medtronic, Merck/MSD, Novartis, Pfizer, Sanofi-Aventis, WebMD, and Zoll. JS reports ownership of CorXL. JS has received grant support through his institution from Abbott, Bayer Healthcare, Biosense Webster, Biotronik, Boston Scientific, Daiichi Sankyo, and Medtronic

Joris R. de Groot received consultant and/or speaker fees from Servier, Daiichi Sankyo, AtriCure Inc., Bayer, Novartis and Itreas. JRdG received grant support through his institution from St Jude Medical/Abbott, Boston Scientific, Medtronic and AtriCure. JRdG reports ownership of RhythmCARE. Pierre Levy acts as a consultant for AbbVie, Actelion, Amgen, Astellas, Bayer, Biogen, Bristol-Myers Squibb, Boehringer Ingelheim, Daiichi-Sankyo, Eli Lilly, Gilead, GSK, Hospira, Impeto Médical, Janssen, MSD, Mundipharma, Novartis, Novo Nordisk, Pfizer, Roche, Sanofi and Sanofi Pasteur MSD.

Ameet Bakhai does not hold any stock but is involved in research sponsored by and is a member of advisory panels and speakers' bureau for Daiichi Sankyo, Pfizer, BMS, Bayer and Boehringer Ingelheim.

Wolfgang Zierhut, Petra Laeis, Michael Kerschnitzki and Paul-Egbert Reimitz are employees of Daiichi Sankyo Europe $\mathrm{GmbH}$, Munich, Germany. Paulus Kirchhof receives research support from European Union, British Heart Foundation, Leducq Foundation, Medical Research Council (UK), and German Centre for Cardiovascular Research, from several drug and device companies active in atrial fibrillation, and has received honoraria from several such companies. PK is listed as inventor on two patents held by University of Birmingham (Atrial Fibrillation Therapy WO 2015140571, Markers for Atrial Fibrillation WO 2016012783).

\section{Author details}

${ }^{1}$ Università degli Studi di Pisa, Pisa, Italy. ${ }^{2}$ HRB Stroke Clinical Trials Network Ireland, University College Dublin, Dublin, Ireland. ${ }^{3}$ Centro Hospitalar e Universitário de Coimbra, Coimbra, Portugal. ${ }^{4}$ Hôpital de la Timone, Marseille, France. ${ }^{5}$ Universitair Ziekenhuis Brussels, Dilbeek, Belgium. ${ }^{6} \mathrm{Hospital}$ Universitario La Paz, IDIPAZ, Madrid, Spain. ${ }^{7}$ Karl Landsteiner Institute for Cardiometabolics and SFU, Vienna, Austria. ${ }^{8}$ University of Munster, Münster, Germany. ${ }^{9}$ University Hospital of Zurich, Zürich, Switzerland. ${ }^{10}$ Amsterdam University Medical Centers/University of Amsterdam, Amsterdam, The Netherlands. ${ }^{11}$ Université Paris-Dauphine, PSL Research University, Paris, France. ${ }^{12}$ Royal Free London NHS Foundation Trust, Chase Farm Hospital, London, UK. ${ }^{13}$ Daiichi Sankyo Europe GmbH, Munich, Germany. ${ }^{14}$ Institute of Cardiovascular Sciences, University of Birmingham, SWBH and UHB NHS Trusts, IBR 136, Wolfson Drive, Birmingham B15 2TT, UK. ${ }^{15}$ The Atrial Fibrillation NETwork (AFNET), Münster, Germany.

\section{Received: 14 March 2019 Accepted: 27 June 2019}

\section{Published online: 12 July 2019}

\section{References}

1. Sankaranarayanan R, Kirkwood G, Visweswariah R, Fox DJ. How does chronic atrial fibrillation influence mortality in the modern treatment era? Curr Cardiol Rev. 2015;11(3):190-8.
2. Connolly SJ, Ezekowitz MD, Yusuf S, Eikelboom J, Oldgren J, Parekh A, et al. Dabigatran versus warfarin in patients with atrial fibrillation. N Engl J Med. 2009;361(12):1139-51.

3. Lip GY, Clemens A, Noack H, Ferreira J, Connolly SJ, Yusuf S. Patient outcomes using the European label for dabigatran. A post-hoc analysis from the RE-LY database. Thromb Haemost. 2014;111(5):933-42.

4. Granger CB, Alexander JH, McMurray JJ, Lopes RD, Hylek EM, Hanna M, et al. Apixaban versus warfarin in patients with atrial fibrillation. $N$ Engl J Med. 2011;365(11):981-92.

5. Patel MR, Mahaffey KW, Garg J, Pan G, Singer DE, Hacke W, et al. Rivaroxaban versus warfarin in nonvalvular atrial fibrillation. $N$ Engl I Med. 2011;365(10):883-91.

6. Giugliano RP, Ruff CT, Braunwald E, Murphy SA, Wiviott SD, Halperin JL, et al. Edoxaban versus warfarin in patients with atrial fibrillation. N Engl J Med. 2013;369(22):2093-104.

7. Kirchhof P, Benussi S, Kotecha D, Ahlsson A, Atar D, Casadei B, et al. 2016 ESC guidelines for the management of atrial fibrillation developed in collaboration with EACTS. Eur Heart J. 2016;37(38):2893-962.

8. European Medicines Agency. Lixiana: summary of product characteristics 2015.

9. Huisman MV, Rothman KJ, Paquette M, Teutsch C, Diener HC, Dubner SJ, et al. The changing landscape for stroke prevention in AF: findings from the GLORIA-AF registry phase 2. J Am Coll Cardiol. 2017;69(7):777-85.

10. Steinberg BA, Simon DN, Thomas L, Ansell J, Fonarow GC, Gersh BJ, et al. Management of Major Bleeding in patients with atrial fibrillation treated with non-vitamin $\mathrm{K}$ antagonist Oral anticoagulants compared with warfarin in clinical practice (from phase II of the outcomes registry for better informed treatment of atrial fibrillation [ORBIT-AF II]). Am J Cardiol. 2017; 119(10):1590-5.

11. Camm AJ, Amarenco $P$, Haas $S$, Hess $S$, Kirchhof $P$, van Eickels $M$, et al. XANTUS: rationale and design of a noninterventional study of rivaroxaban for the prevention of stroke in patients with atrial fibrillation. Vasc Health Risk Manag. 2014;10:425-34.

12. Camm AJ, Accetta G, Ambrosio G, Atar D, Bassand JP, Berge E, et al. Evolving antithrombotic treatment patterns for patients with newly diagnosed atrial fibrillation. Heart. 2017;103(4):307-14.

13. Eikelboom JW, Weitz JI. 'Realworld' use of non-vitamin K antagonist oral anticoagulants (NOACs): lessons from the Dresden NOAC registry. Thromb Haemost. 2015;113(6):1159-61.

14. Hanon O, Vidal JS, Le Heuzey JY, Kirchhof P, De Caterina R, Schmitt J, et al. Oral anticoagulant use in octogenarian European patients with atrial fibrillation: a subanalysis of PREFER in AF. Int J Cardiol. 2017;232:98-104.

15. Boriani G, Proietti M, Laroche C, Diemberger I, Popescu MI, Riahi S, et al. Changes to oral anticoagulant therapy and risk of death over a 3year follow-up of a contemporary cohort of European patients with atrial fibrillation final report of the EURObservational research Programme on atrial fibrillation (EORP-AF) pilot general registry. Int J Cardiol. 2018;271:68-74

16. Pottegard A, Grove EL, Hellfritzsch M. Use of direct oral anticoagulants in the first year after market entry of edoxaban: a Danish nationwide drug utilization study. Pharmacoepidemiol Drug Saf. 2018;27(2):174-81.

17. Coleman Cl, Antz M, Bowrin K, Evers T, Simard EP, Bonnemeier H, et al. Realworld evidence of stroke prevention in patients with nonvalvular atrial fibrillation in the United States: the REVISIT-US study. Curr Med Res Opin. 2016;32(12):2047-53.

18. Coleman $\mathrm{Cl}$, Antz M, Ehlken B, Evers T. REal-Llfe evidence of stroke prevention in patients with atrial fibrillation-the RELIEF study. Int J Cardiol. 2016;203:882-4.

19. Deitelzweig S, Luo X, Gupta K, Trocio J, Mardekian J, Curtice T, et al. Comparison of effectiveness and safety of treatment with apixaban vs. other oral anticoagulants among elderly nonvalvular atrial fibrillation patients. Curr Med Res Opin. 2017;33(10):1745-54.

20. Serebruany V, Cherepanov V, Fortmann S, Kim MH. Mortality and oral anticoagulants in the Food and Drug Administration adverse event reporting system. Open Heart. 2017:4(2):e000629.

21. De Caterina R, Kelly P, Monteiro P, Deharo JC, de Asmundis C, López-de-Sá $E$, et al. Design and rationale of the edoxaban treatment in routiNe clinical prActice for patients with atrial fibrillation in Europe (ETNA-AF-Europe) study. J Cardiovasc Med (Hagerstown). 2019;20(2):97-104.

22. Kotecha D, Bax JJ, Carrera C, Casadei B, Merkely B, Anker SD, et al. Roadmap for cardiovascular education across the European Society of Cardiology: inspiring better knowledge and skills, now and for the future. Eur Heart J. 2018;40(21):1728-38. 
23. Nielsen PB, Skjoth F, Sogaard M, Kjaeldgaard JN, Lip GY, Larsen TB. Effectiveness and safety of reduced dose non-vitamin $\mathrm{K}$ antagonist oral anticoagulants and warfarin in patients with atrial fibrillation: propensity weighted nationwide cohort study. Bmj. 2017:356:510.

24. Barra ME, Fanikos J, Connors JM, Sylvester KW, Piazza G, Goldhaber SZ. Evaluation of dose-reduced direct Oral anticoagulant therapy. Am J Med. 2016;129(11):1198-204

25. Lavoie K, Turgeon MH, Brais C, Larochelle J, Blais L, Farand P, et al. Inappropriate dosing of direct oral anticoagulants in patients with atrial fibrillation. J Atr Fibrillation. 2016;9(4):1478.

26. Yao X, Shah ND, Sangaralingham LR, Gersh BJ, Noseworthy PA. Non-vitamin $\mathrm{K}$ antagonist Oral anticoagulant dosing in patients with atrial fibrillation and renal dysfunction. J Am Coll Cardiol. 2017;69(23):2779-90.

27. Yamashita T, Koretsune Y, Yang Y, Chen SA, Chung N, Shimada YJ, et al. Edoxaban vs. warfarin in east Asian patients with atrial fibrillation- an ENGAGE AF-TIMI 48 subanalysis. Circ J. 2016;80(4):860-9.

28. Steffel J, Verhamme P, Potpara TS, Albaladejo P, Antz M, Desteghe L, et al. The 2018 European heart rhythm association practical guide on the use of non-vitamin $\mathrm{K}$ antagonist oral anticoagulants in patients with atrial fibrillation. Eur Heart J. 2018;39(16):1330-93.

\section{Publisher's Note}

Springer Nature remains neutral with regard to jurisdictional claims in published maps and institutional affiliations.

Ready to submit your research? Choose BMC and benefit from:

- fast, convenient online submission

- thorough peer review by experienced researchers in your field

- rapid publication on acceptance

- support for research data, including large and complex data types

- gold Open Access which fosters wider collaboration and increased citations

- maximum visibility for your research: over $100 \mathrm{M}$ website views per year

At BMC, research is always in progress.

Learn more biomedcentral.com/submissions 